\title{
Understanding Camellia sinensis using Omics Technologies along with Endophytic Bacteria and Environmental Roles on Metabolism: A Review
}

\author{
Phumudzo Patrick Tshikhudo ${ }^{1}\left(\mathbb{D}\right.$, Khayalethu Ntushelo ${ }^{1}$, Fhatuwani Nixwell Mudau ${ }^{1}(\mathbb{D}$, \\ Bahare Salehi ${ }^{2, *}(\mathbb{D})$, Mehdi Sharifi-Rad ${ }^{3, *}$, Natália Martins ${ }^{4,5, *} \mathbb{D}$, Miquel Martorell ${ }^{6}(\mathbb{D})$ and \\ Javad Sharifi-Rad $7,8, *$ (D) \\ 1 Department of Agriculture and Animal Health, College of Agriculture and Environmental Sciences, \\ University of South Africa, Private Bag X6, Florida 1710, South Africa; tshikhudopp@gmail.com (P.P.T.); \\ ntushk@unisa.ac.za (K.N.); mudaufn@unisa.ac.za (F.N.M.) \\ 2 Student Research Committee, School of Medicine, Bam University of Medical Sciences, Bam 44340847, Iran \\ Department of Medical Parasitology, Zabol University of Medical Sciences, Zabol 61663335, Iran \\ 4 Faculty of Medicine, University of Porto, Alameda Prof. Hernâni Monteiro, 4200-319 Porto, Portugal \\ Institute for Research and Innovation in Health (i3S), University of Porto-Portugal, 4200-135 Porto, Portugal \\ 6 Department of Nutrition and Dietetics, Faculty of Pharmacy, University of Concepcion, VIII-Bio Bio Region, \\ Concepcion 4070386, Chile; mmartorell@udec.cl \\ 7 Food Safety Research Center (salt), Semnan University of Medical Sciences, Semnan 3519899951, Iran \\ 8 Department of Chemistry, Richardson College for the Environmental Science Complex, The University of \\ Winnipeg, Winnipeg, MB R3B 2G3, Canada \\ * Correspondence: bahar.salehi007@gmail.com (B.S.); m.sharifirad@zbmu.ac.ir (M.S.-R.); \\ ncmartins@med.up.pt (N.M.); javad.sharifirad@gmail.com (J.S.-R.); Tel.: +98-21-8877-7539 (B.S.); \\ +98-54-322-51-790 (M.S.-R.); +351-22-5512100 (N.M.); +98-21-88200104 (J.S.-R.)
}

Received: 13 December 2018; Accepted: 8 January 2019; Published: 14 January 2019

\begin{abstract}
Camellia sinensis is the most consumed beverage worldwide. It contains a wide variety of secondary metabolites, such as alkaloids, saponins, tannins, catechins, and polyphenols, generated through a condensation reaction of cinnamic acid with three malonyl-CoA groups. In addition to the metabolic processes occurring within this plant, there are also some plant-associated bacterial endophytes. These bacteria reside in the living tissues of the host plants without causing any harmful effect to them, thereby stimulating secondary metabolite production with a diverse range of biological effects. Omics technologies reveal understanding of the biological phenomena of transcriptomics, proteomics, and metabolomics. In this sense, the present review aims to provide a comprehensive review of various methods used to identify distinct plant compounds, namely transcriptomic, proteomic, and metabolomic analysis. The role of endophytic bacteria in C. sinensis metabolism, and C. sinensis antioxidant and antimicrobial effects, are also carefully highlighted.
\end{abstract}

Keywords: Camellia sinensis; endophytic bacteria; metabolomics; proteomics; transcriptomics; antioxidant; antimicrobial; phenolic compounds

\section{Introduction}

Camellia sinensis (L.) Kuntze. (green tea) produces a common herbal drink that is used by many nations around the world, and is ranked second after water in terms of popularity and preference [1-3]. Although C. sinensis is native to China [4], it is now commercially grown in both tropical and subtropical parts of the world [5].

Certain biological phenomena may be revealed through transcriptional regulation (transcriptomics), genes end-products (proteomics), and metabolic product (metabolomics) 
analysis [6]. The huge bioinformatics database of various plant species has been rapidly accumulated and is widely used for molecular analyses of secondary metabolism, abiotic stress tolerance, and so on. Plants provide teas to human consumption, and about $80 \%$ of the worldwide population relies on traditional teas for primary health care, especially in Asian and African countries [7]. Green tea contains about 4000 bioactive compounds, of which polyphenols represented one-third [8]. Green tea phytochemicals' screening revealed the presence of alkaloids, saponins, tannins, catechin, and polyphenols (Figure 1), which are considered tea quality parameters [9].

Living herbal medicine-associated endophytic bacteria reside in the internal tissues of the host plants without causing any harmful effect, thereby stimulating secondary metabolites production with various biological activities [10]. Bacterial endophytes may also be beneficial to their hosts, producing a wide range of natural products that could be harnessed for potential use in medicinal, agricultural, or environmental fields [11]. Some of the endophytic bacteria may produce the same secondary metabolites as plants, making them a promising source of novel compounds [10]. Endophytic bacteria colonize internal tissues to form symbiotic, mutualistic, commensal, and trophobiotistic host relationships. Several endophytic bacteria appear to derive from rhizosphere or phyllosphere; some of them may be transmitted through seeds of the parent plant. In addition, endophytic bacteria can promote plant growth and can act as biocontrol agents. Many endophytes are members of the Pseudomonas, Burkholderia, and Bacillus genera, which are known for their wide range of secondary metabolic products, including antimicrobials, growth promoting molecules, and volatile organic compounds [11].

\begin{tabular}{|l|l|}
\hline Other chemical compounds & Phenolic compounds \\
\hline Aminoacids & Apigenin glucosyl arabinoside \\
Caffeine & Epicatechin \\
Fructose & Epicatechin gallate \\
Glucose & Epigallocatechin \\
Sucrose & Epigallocatechin-3-gallate \\
Theanine & Gallic acid \\
Strictinin & Gallocatechin \\
Pyroglutamic & Kaempferol $p$-coumaroylglucosylrhamnosylgalactoside \\
& Malic acid \\
& Quercetin $p$-coumaroylglucosylrhamnosylgalactoside \\
& Quinic acid \\
& Succinic acid \\
\hline
\end{tabular}

Figure 1. Chemical compounds in Camellia sinensis.

In this sense, using several literature sources, this paper intensively reviews various methods for transcriptomics, proteomics, and metabolomics analysis, that can be used to identify distinct plant compounds. The role of endophytic bacteria in C. sinensis metabolism is also reviewed, and C. sinensis antioxidant and antimicrobial properties carefully highlighted (Figure 2). 


\section{Camellia sinensis}

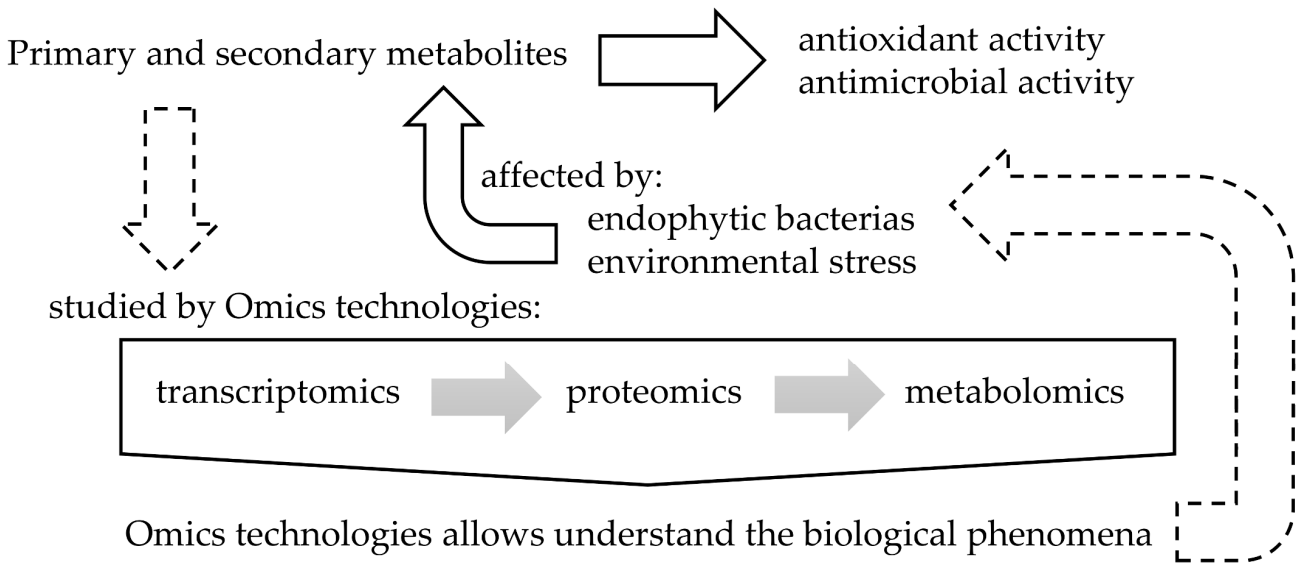

Figure 2. Role of endophytic bacteria and environmental stress on primary and secondary metabolites that affect antioxidant and antimicrobial activities of Camellia sinensis, and how omics technologies allow understanding of these biological phenomena.

\section{Transcriptomics}

Transcriptomics provide information on the occurrence and relative abundance of RNA transcripts, indicating the active components within cell [12]. Serial analysis of gene expression and microarrays have been applied to many model systems, aiming to study the predominantly expressed genes in stem cells. The resulting sequence typically reads 30 to 400 base pairs in length, commonly aligned to a reference genome and assessed for quality, depending on DNA-sequencing technology used. Data processing and quality assessment tools generally provide diagnostic visualizations [13].

Using the Illumina sequence analytical method, Wang, et al. [14] obtained about 57.35 million RNA-Seq reads pooled into 216.831 transcripts, with an average length of $356 \mathrm{bp}$ and an N50 of $529 \mathrm{bp}$. Analysis of pathways showed that both carbohydrate metabolism and calcium signaling pathways could play an important role in C. sinensis cold stress responses. The transcriptome from poly (A) + RNA of $C$. sinensis was analyzed at an unprecedented depth (2.59 gigabase pairs) by Shi et al. [15] in order to identify most of the genes associated with flavonoid, theanine, and caffeine biosynthetic pathways. Tan et al. [16] analyzed a floral transcriptome of $C$. sinensis and assembled 26.9 million clean readings in 75.531 unigenes, averaging $402 \mathrm{bp}$. Both C. sinensis transcriptome information and genetic maps provide a valuable basis for molecular biology investigations, such as functional gene isolation, quantitative trait loci mapping, and marker-assisted selection breeding in this important species.

MicroRNAs (miRNAs) are small RNAs endogenous that have an important role in plant development and growth, as well as in stress responses [17]. C. sinensis has 47.452 expressed sequence tags (EST) available and 14 new $C$. sinensis miRNAs were identified by EST analysis. These miRNAs target 51 mRNAs, which can act as transcription factors and participate in several cell process such as oxidation-reduction, transmembrane transport, signal transduction, and stress response. Indeed, gene ontology analysis based on these targets suggested that 37 biological processes were involved, and the Kyoto Encyclopedia of Genes and Genomes pathway enrichment analysis inferred that the identified miRNAs participate in 13 metabolic networks. Jaiprakash et al. [18] applied an RNA isolation protocol that used guanidine hydrochloride on lyophilized leaves of $C$. sinensis. Thus, the use of lyophilized tissues for RNA isolation from tea leaves was explored. High RNA yields ( $500 \mu \mathrm{g} / \mathrm{g}$ dry weight of leaf tissue) were obtained, and RNA was suitable for Northern blotting, reverse transcription, and microarray analysis. Therefore, it was revealed that RNA obtained from lyophilized leaf has high quality, and is undegraded and useful for all downstream applications [18]. In a comparative transcriptome analysis by RNA-sequencing, it was elucidated that exogenous calcium increased C. sinensis thermotolerance [19]. 


\section{Proteomics}

Proteomics provides expertise in identifying and quantifying the cellular levels of each protein encoded by the genome [12]. The most popular methods are based on the combination of two-dimensional gel electrophoresis with mass spectrometry (MS). Other methods, such as high-throughput, quantitative, and western-blot analysis have also been implemented, but require extraordinary resources and efforts. With these methods, the proteomes of several cell structures and organelles, such as the mitochondria and cytoskeleton, can be assessed. In MS experiments, compounds are identified by accurate measurements of their mass-to-charge ratios [13]. In proteomic analysis, typical MS data sets are formed by a list of proteolytic peptides characterized by their mass-to-charge ratios (MS spectra, MS1). Moreover, these peptides may be further fragmented and measured from the resulting mass spectra (MS-MS spectra or tandem MS spectra, MS2), and this information may be used to deduce their sequences. In some complex samples, a fractionation followed by a separation of proteolytic peptides using high performance liquid chromatography (HPLC) prior to MS analysis (LC-MS) should be performed. Several search engines have been developed to predict peptides and proteins $[20,21]$, comparing experimentally measured spectra with theoretical spectra.

The reliability of a given protein or peptide identification is measured by quality scores. The overall quality of entire MS data sets is commonly measured by the false discovery rate (FDR), which is the "expected" proportion of incorrect assignments among the accepted assignments. One of the most popular approaches to calculate FDR is based on target-decoy database use. In addition, several MS visualization tools has been developed [13].

MS-based proteomics is becoming the standard approach for systematic characterization of post-translational modifications, e.g., phosphorylation, glycosylation, ubiquitination or sumosylation, acetylation, and methylation [22]. Post-translational modifications are important biochemical processes for regulating various signaling pathways and determining specific cell fate. Therefore, the identification and comprehension of these covalent modifications is critical in the study of the phytochemicals present in plants and the external factors that affect its composition. Li et al. [23] compared the protein complement of $C$. sinensis tea pollen under different storage conditions. Protein was partially identified using a combination of two-dimensional polyacrylamide gel electrophoresis (2DPAGE), matrix-assisted laser desorption-ionization time-of-flight mass spectrometry (MALDI-TOF/MS), MASCOT, and Xproteo search engine. The analysis revealed that more stress response-related proteins, nucleic acid and fat metabolisms, and membrane transport are lost at room temperature than at $-20{ }^{\circ} \mathrm{C}$, while defense- and energy metabolism-related proteins showed a reverse relationship. A rapid quality control methodology was developed for $C$. sinensis arabinogalactan proteins (AGP) [24]. Using vectorial angle method and IR spectrum analysis, the $1200-800 \mathrm{~cm}^{-1}$ region in second-derivative IR spectra was determined as the key fingerprinting region of $C$. sinensis AGP, with the 1090-900 $\mathrm{cm}^{-1}$ region reflecting its common and conservative characteristics. The major monosaccharides showed intense peaks at about $1075 \mathrm{~cm}^{-1}$ (galactose) and $1045 \mathrm{~cm}^{-1}$ (arabinose), and uronic acids at about $1018 \mathrm{~cm}^{-1}$ in second-derivative IR spectra. About $1134-1094 \mathrm{~cm}^{-1}$ and $900-819$ $\mathrm{cm}^{-1}$ of the variable region was identified, and this was probably due to compositional and structural differences between AGPs. The constructed methodology was tested on C. sinensis AGP extracted by 3 treatments and purified for apparent homogeneity as water-, pectinase-, and trypsin-extracted $C$. sinensis AGP, with an Arabinose/Galactose ratio of 1.37, 1.57, and 1.82, respectively [24].

\section{Metabolomics}

Primary and secondary plant metabolites are final receptors of cell biological information flow and their levels effect protein stability and gene expression [25]. Measurements of these metabolites reflect the plant cellular state and produce critical insights into cellular processes that control biochemical phenotypes of the cell, tissue, or even whole organism. Metabolomics allows evaluation of medicinal plants, not only on the basis of pharmacologically important metabolites, but also based on the fingerprints of minor metabolites and bioactive molecules [26,27]. Further, metabolomics 
can also be used for a better characterization and on quality control of plant extracts, tinctures, and phytotherapeutic products [26].

In fact, metabolomics is conceived as the comprehensive, qualitative, and quantitative study of all the small molecules in an organism [28]. The four conceptual approaches in metabolomics are:

(1) Target analysis;

(2) Metabolite profiling;

(3) Metabolomics; and

(4) Metabolic fingerprinting [29].

Target analysis covers the identification and quantification of a small set of known metabolites (targets) using a particular analytical technique, with best performance for the chemicals of interest. Metabolomics employs complementary analytical methods to determine and quantify the largest possible number of metabolites, either identified or unknown. Metabolic fingerprinting is applied to generate a metabolic signature or mass profile of the sample of interest for comparison with a large sample population, to track differences between samples.

Metabolomics discipline allows one to identify the complete set of metabolites in the cell [12]. Medicinal plant metabolomes are of particular interest as a valuable natural resource for evidence-based development of new phytotherapeutic agents and nutraceuticals [30-34]. Platforms dedicated to compare metabolomics are evolving into new technologies to monitor drug metabolism, chemical toxicology, and disease development. Non-target metabolomics is a useful method for the simultaneous analysis of many compounds present in herbal products. LC-MS can determine presence, amount, and sometimes structure of plant metabolites in complex plant mixtures. Nuclear magnetic resonance (NMR) is a common method used in metabolomics, and in contrast to MS-based approaches, in most cases an analytic separation is not required [13]. Pattern recognition, such as principal component analysis (PCA), partial least squares discriminant analysis (PLS-DA), and batch-learning self-organizing map (BL-SOM) analysis are usually employed to reduce a metabolite fingerprint and to classify the analyzed samples [27]. PCA and PLS-DA are latent variable methods, where new components are computed as linear combinations of the original variables. PCA is an unsupervised method and PLS-DA is a supervised method, where the information about each sample's group is defined. Metabolomics typically use multivariate analysis to statistically process the huge amount of analytical chemistry data. PCA and hierarchical cluster analysis allow differentiation of green tea samples from black tea samples [35].

The study of the chemical composition of a typical tea beverage shows that the primary metabolite content is similar (\% wt/wt solids) in green and black tea, with $3 \%$ amino acids, $6 \%$ peptides and proteins, $2 \%$ organic acids, $7 \%$ sugars, $4 \%$ other carbohydrates, and $3 \%$ lipids in both [36]. C. sinensis leaf contains a very high level of polyphenols, especially flavonoids, an important characteristic that distinguishes it from other plants [37]. These flavonoids and their oxidative products, formed through fermentation and drying processes, largely produces the color and taste of black tea. The flavonoids content of various tea clones correlates with chalcone synthase activity in tea leaf. Le Gall et al. [38] collected $C$. sinensis from various countries for metabolomics analysis by ${ }^{1} \mathrm{H} N \mathrm{NR}$, in order to establish whether teas could be discriminated according to the country of origin or with respect to quality. With PCA application, it was found that Longjing teas (highest quality Chinese tea), compared to other teas, had higher levels of theanine, gallic acid, caffeine, epigallocatechin-3-gallate (EGCG), and epicatechin (EC) gallate, and lower levels of epigallocatechin (EGC). The different cultivation methods affect green tea quality by altering the metabolomics profile $[37,39]$.

Metabolome changes were investigated in green tea and shade cultured $C$. sinensis by LC-MS and gas chromatography-mass spectrometry (GC-MS) coupled with a multivariate dataset [40]. PCA and orthogonal projections to latent structures DA (OPLS-DA) of green tea clearly showed higher levels than tencha of galloylquinic acid, EGC, EC, succinic acid, and fructose, along with lower levels of gallocatechin, strictinin, apigenin glucosyl arabinoside, quercetin 
p-coumaroylglucosylrhamnosylgalactoside, kaempferol $p$-coumaroylglucosylrhamnosylgalactoside, malic acid, and pyroglutamic acid. The effects of climatic conditions on C. sinensis metabolites in three different growing areas of Jeju Island, South Korea, were investigated through ${ }^{1} \mathrm{H}$ NMR spectroscopy [41]. Pattern recognition methods, such as OPLS-DA and PCA, revealed clear discriminations of green teas from the different growing areas. Variations of theanine, quinic acid, glucose, EC, EGC, EGCG, caffeine, and amino acid profile were responsible for the discriminations. The dependence of global $C$. sinensis metabolome on plucking positions was investigated through ${ }^{1} \mathrm{H}$ NMR analysis coupled with multivariate statistical dataset [42]. OPLS-DA and PCA were employed to find a metabolic discrimination among fresh $C$. sinensis leaves plucked at different positions, from old to young leaves. The results showed a clear metabolic discrimination among C. sinensis leaves (increased levels of theanine, caffeine, and gallic acid levels, and decreased levels of catechins, glucose, and sucrose) as the green tea plant grows up. Moreover, a different metabolism of the tea plant was observed between the tea leaf and stem.

Seasonal variations of phenolic compounds were studied, using a HPLC method, in fresh tea shoots grown in Australia [43]. The content of EGCG, ECG, and CG were higher in fresh tea shoots in the warm months and lower in the cool months. Mechanisms that induce seasonal variations in tea shoots may be day length, sunlight, and temperature, which vary markedly across seasons. In another study, GC coupled with time-of-flight MS and multivariate data analysis was employed to evaluate green tea quality, showing changes dependent on green tea varieties and manufacturing processes [44].

In conclusion, the synthesis of several phenolic compounds, such as EGCG, ECG, and CG, related with tea quality, is temperature sensitive or dependent $[43,45,46]$. Moreover, it has also been suggested that EGCG synthesis depends on daytime length or stronger sunlight during the summer months $[36,39]$.

\section{Role of Endophytic Bacteria in Camellia sinensis Metabolism}

Endophytic bacterial species, such as Azospirillum species, Bacillus pumilus, Bacillus megaterium, Bacillus amyloliquefaciens, Beijerinckia species, Paenibacillus polymyxa, Pseudomonas aeruginosa, Comamonas acidovorans, and Serratia marcescens have proven to promote C. Sinensis growth through inducing indole-3-acetic acid (IAA), ammonia and siderophore production, phosphate solubilization, and exerting antagonism against pathogens [2,47-53].

Endophytes-derived bioactive natural products are promising resources for medicinal, agricultural, and other related industries [54]. Different kinds of alkaloids have contributed to plant defense through endophytes action. Some of these alkaloids are growth-promoting compounds, and some have an important role in plants' resistance to environmental stress. Amines and amides are very common metabolite products from endophytes and are stated as being toxic to insects. IAA is a well-known phytohormone that can be produced by endophytes. Other bioactive compounds, such as steroids, terpenoids, and diterpenes are also generated by endophytes [55], responsible for promoting plant growth and yield, suppress pathogens growth and colonization, help in removing contaminants, solubilize phosphate, and even contribute to plant-assimilable nitrogen [56]. Thus, the proper implementation of these plant growth-promoting endophytic bacteria may be helpful in organic tea plantation $[53,57]$ (Table 1$)$. 
Table 1. Roles of endophytic bacteria from Camellia sinensis.

\begin{tabular}{cc}
\hline Role & References \\
\hline Increase defense-related enzymes & {$[47,49,58,59]$} \\
Increase nitrogen fixation & {$[51,53,60]$} \\
Increase polyphenolic amount & {$[47,49,58,59]$} \\
Indole-3-acetic acid secretion & {$[47,51,52,57-59]$} \\
Inhibition of pathogen growth & {$[2,49,51,57-59]$} \\
Phosphate solubilizers & {$[47-51,53,58-60]$} \\
Positive plant growth & {$[2,47-49,51-53,57,58,60]$} \\
Siderophore producers & {$[53,58,59]$} \\
\hline
\end{tabular}

Nath, Sharma, and Barooah [53] isolated endophytic bacteria from C. sinensis roots and screened it for multiple plant growth promoting activities, including phosphate solubilization and indole acetic acid, ammonia, and siderophore production. These isolates were found to be siderophore producers, phosphate solubilizers, and ammonia producers. In vivo studies revealed that B. megaterium has a marked ability to promote tea plant growth [47]. Fomes lamaoensis population in soil before and after B. megaterium application, as determined by enzyme-linked immunosorbent assay (ELISA) and dot-blot, has risen against the pathogen, which is shown to be greatly reduced in the presence of the bacterium. B. megaterium root colonization and subsequent inoculation with $F$. lamaoensis also led to an increase in polyphenolic compounds, as well as in defense-related enzymes. The analysis for B. megaterium mechanism of action determination revealed that this bacterium is able to solubilize phosphate, to produce IAA, siderophore, and antifungal metabolites. B. pumilus, isolated from tea rhizosphere, was evaluated for its plant growth promoting and bio-control effects, both in vitro and in vivo [58]. B. pumilus showed positive plant growth promoting rhizobacteria (PGPR) traits in vitro, such as phosphate solubilization, IAA secretion, and siderophore production. B. pumilus inhibited the growth of tea root fungal pathogens, such as Poria hypobrunnea, F. lamaoensis, Sphaerostilbe repens, Scleorotinia sclerotiorum, and Sclerotium rolfsii. This bacterium was also able to reduce tea root caused by P. hypobrunnea. Moreover, the authors found enhanced accumulation of phenolics and an improvement in defense enzymes (i.e., peroxidase, phenyl alanine ammonia lyase, beta-1,3-glucanase, and chitinase) activities, that reveals systemic-acquired resistance (SAR) activation in tea plants. Also, HPLC analysis of catechins revealed the appearance of dimers and isomers during tea fermentation [60].

Chakraborty et al. [59] explored the potential of microorganisms from C. sinensis rhizosphere for the overall improvement of tea growth and productivity. B. amyloliquefaciens, S. marcescens, and B. pumilus showed positive PGPR traits in vitro, such as phosphate solubilization and production of siderophore, IAA, and antagonism to pathogens. Then, 16S rDNA sequencing of the bacteria was done, and their phylogenetic relationships determined. PGPR application led to an enhancement in defense-related enzyme activity in tea leaves (phenyl alanine ammonia lyase, peroxidase, chitinase, and beta-1,3-glucanase). Total phenols also increased quantitatively. Thus, it becomes evident that PGPR application in the soil led to plants biopriming.

B. pumilus from tea's rhizosphere was in vitro and in vivo evaluated for its plant growth promoting and biocontrol activities [58]. This bacterium showed positive PGPR traits in vitro and inhibited tea root fungal pathogen growth, such as P. hypobrunnea, F. lamaoensis, S. repens, S. sclerotiorum, and S. rolfsii. Moreover, it enhanced phenolics accumulation and defense enzymes, and revealed a great ability to activate SAR in tea plants. Plant growth promoting ability of B. megaterium isolated from tea bushes rhizosphere was tested on five varieties of tea in potted conditions and in the experimental field [49]. The results of this study showed an increase in height, emergence of new leaves, branches, and an increase in leaf numbers, as well as an increase in leaf dry mass following application of this bacterium. An increase in leaves and branch numbers was prominent after 12 months of application in field, but in potted plants a significant increase was obtained even after 2 months of application. A significant increase in phenolic compound accumulation and chlorophyll content was also stated in tea leaves. B. megaterium was able to solubilize phosphate in vitro and in vivo. Following application 
of this bacterium, soil phosphatase activities were enhanced, soil phosphorus $(\mathrm{P})$ content decreased, and root and leaf phosphate increased.

Rooting induction from C. sinensis cuttings by 2000 ppm indole-3-butyric acid (IBA) and PGPR treatments was done under controlled conditions [52]. The cuttings were sampled and treated with 7 bacteria strains, including Bacillus species, P. polymyxa, C. acidovorans, and 2000 ppm IBA. All bacteria showed IAA producing capacity and higher rooting percentages compared with the control treatment. B. megaterium and S. marcescens were isolated from tea rhizosphere, enhanced tea varieties growth in the experimental field, as well as in nursery, as evidenced by increase in height and emergence of new leaves and branches [48]. Both B. megaterium and S. marcescens were able to solubilize phosphate in vitro and in vivo. Soil phosphate content decreased due to phosphate-solubilizing bacteria (PSB) activity, while root and leaf phosphate contents increased. Both acid and alkaline phosphatase activities in rhizosphere soil of all 5 varieties were enhanced following bacteria application. Thus, tea rhizosphere is a good habitat for PGPR strains represented by Bacillus and Pseudomonas species [60]. Several nitrogen fixers, phosphate solubilizers, and actinomycetes were isolated from tea rhizospheric soil. Microbial strains having plant growth promoting potential were screened in the pot trial. From these, 12 strains were subjected to greenhouse trial, and showed maximum gain in biomass weight of tea plants. This was followed by a field experiment with the same microbial strains as foliar spray to determine their effect on fresh leaf yield. Morang, Dutta, Kumar, and Kashyap [2] isolated and identified P. aeruginosa from C. sinensis plantation soil of Barak Valley, Assam, India. This bacterium showed biocontrol and growth promotion potential against the tea root pathogen Fomes lamoensis in infested 1-year old tea plants under nursery conditions [2].

In the investigations carried out on plant growth promoting tea plants rhizomicroorganisms, Azospirillum, and Beijerinckia, PSB and fluorescent pseudomonads and Bacillus species were isolated from tea plant rhizospheres [51]. The amount of nitrogen fixed by Azospirillum isolates ranged from 7.23 to $22.16 \mathrm{mg} / \mathrm{g}$ malate. Beijerinckia isolates led to nitrogen fixation, ranging from 2.86 to $5.54 \mathrm{mg} / \mathrm{g}$ of glucose, and produced both IAA and GA, which ranged from 53 to $169 \mu \mathrm{g}$ and from 44 to $90 \mu \mathrm{g} / \mathrm{L}$ broth, respectively. Fluorescent pseudomonads solubilized tricalcium phosphate in the range of 9.39 to $22.97 \%$, and showed in vitro inhibitory activity against plant pathogenic fungi, namely Pestolotia thea, Fusarium oxysporum, Rhizoctonia bataticola, and S. rolfsii. The biocontrol mechanisms in the antagonistic isolates included siderophores, volatile compounds, and antimicrobial metabolite production. Moreover, Azospirillum isolates and 7 each of phosphate solubilizing bacteria and fluorescent pseudomonads significantly improved growth, dry matter content, and nutrient uptake of tea plants over control.

Nitrogen fixing Azospirillum and phosphate solubilizing bacteria were isolated from selected tea soils of southern India [50], and a technology for their mass multiplication was developed. Biofertilizers showed higher yield at the rate of $5 \mathrm{~g} /$ seedling, with $15 \mathrm{~g}$ of formulation/bush.

\section{Antioxidant and Antimicrobial Properties of Camellia sinensis}

C. sinensis leaves contain polyphenols, which have remarkable antioxidant and antimicrobial effects against Staphylococcus aureus, Vibrio cholerae, Campylobacter jejuni, Stapylococcus epidermidis, Vibrio mimicus, Listeria monocytogenes, Escherichia coli, Salmonella typhi, P. aeruginosa, Helicobacter pylori, and Propionibacterium acnes, amongst others $[8,9,62-70]$. The antibacterial activity of black tea extract against several pathogenic bacteria, including Gram-positives (L. monocytogenes and $S$. aureus) and Gram-negatives ( $V$. cholerae and Salmonella enterica serovar), was investigated by Mandal, DebMandal, Pal, and Saha [67]. Kumar et al. [66] conducted a study on green tea leaf extracts to test their antibacterial activity against various bacteria isolated from environmental sources. The chemotherapeutic use of green tea was clearly reflected. All bacterial isolates were identified by Gram staining and biochemical testing. Six different bacteria were identified, including E. coli, Staphylococcus, Streptococcus, Pseudomonas, Bacillus, and Proteus species. The antibacterial activities of extracts were checked by disc diffusion assay. Catechins EGCG, EGC, ECG, EC, and gallocatechin-3-gallate (GCG) were evidenced to play an important role in green tea's inhibition of 
bacterial growth, involving damage in bacterial cell membranes [71]. The green sorts of tea have shown higher antimicrobial activity than the black ones, due to different phytochemical patterns. Indeed, daily consumption of green tea is able to kill Gram positive S. aureus, including many other harmful bacteria.

On the other hand, constituents present in tea also possess antimicrobial, anticarcinogenic, and anti-mutagenic properties [67]. The antimicrobial activity of plant extracts also depends on presence of different secondary metabolites, like hydroxyl group on active constituents. These biologically active compounds of plant extracts are considered antimicrobial agents, which are able to inhibit cell wall, protein, and nucleic acid synthesis [71]. EGCG have been reported to have antimicrobial properties [68]. The antimicrobial activity of different tea extracts was evaluated by Spot-On-Lawn and Well Diffusion assays, and the minimum inhibitory concentration (MIC) was determined. These three methods used showed Brochothrix thermosphacta inhibition, while Pseudomona putida and E. coli inhibition were only detected with MIC assay. Indeed, MIC determination in broth culture appeared to be the most reliable method to determine the effective inhibitory activity of catechin compounds.

An acidic polysaccharide from C. sinensis was examined by Lee, et al. [72] to characterize its anti-adhesive effects against pathogenic bacteria, most notably H. pylori, P. acnes, and S. aureus. This acidic polysaccharide showed marked inhibitory effects against pathogen-mediated hemagglutination. $C$. sinensis has been shown to possess antimicrobial properties and to lower the risk of cardiovascular and periodontal diseases [73]. In this study, the antimicrobial effects of brewing green tea were investigated against common oral bacteria, such as Streptococcus mutans, Porphyromonas gingivalis, and S. epidermis. Gram stain tests revealed that these cultures had a mixture of Gram-positive and Gram-negative bacteria. MIC assay implied a positive correlation between green tea concentration and bacterial growth.

C. sinensis crude extracts inhibited in vivo growth of Candida albicans, Candida glabrata, Candida tropicalis, Candida krusei, and Microsporum persicolor [74]. Simonetti et al. [75] demonstrated that C. sinensis has antibacterial and antifungal activities in combination with butylated hydroxyanisole (BHA). Green tea glycolic extract showed only limited activity against $S$. mutans and no activity against C. albicans and certain E. coli strains. BHA, at non-inhibitory concentrations, increased the microbicidal activity of green tea against S. mutans, non-susceptible E. coli, and C. albicans. On the other hand, green tea in combination with BHA reduced S. mutans hydrophobicity and greatly inhibited C. albicans hyphae formation. The mechanism involved in the increased antimicrobial activity of green tea seems to be related to an impairment of the barrier function in microorganisms and a depletion in thiol groups. Tea chloroform and petroleum ether extracts showed strong antibacterial activities against $B$. subtilis and P. aeruginosa, while other extracts were less active [65]. The MIC value of tea chloroform extract was found to be $25 \mu \mathrm{g} / \mathrm{mL}$. The antibacterial activities of Kenyan and Nigerian tea bag extracts were tested against S. aureus, P. aeruginosa, V. cholerea, E. coli, and Salmonella and Proteus species using agar-gel diffusion method [9]. Results obtained showed that $20 \%$ extract of both teas exerted antibacterial activities against S. aureus, E. coli, V. cholerea, and Proteus species. Archana and Abraham [69] evaluated and compared $C$. sinensis fresh leaves, commercial green tea leaves, and dust tea antimicrobial effects against enteropathogens and specific fungi, using well diffusion and paper disk diffusion assays, and MIC determination. Synergistic activity of green tea and commercial antibiotic chloramphenicol was also analyzed.

Catechin (the major green tea polyphenols) antibacterial effects were studied using Clostridium and Bacillus species spores [63]. Clostridium botulinum and Bacillus cereus vegetative growth was inhibited by catechins' crude extracts. Low catechins concentrations, although requiring a long exposure time, markedly inhibited bacterial spores' growth. Indeed, spores are generally resistant to many disinfectants, but here were sensitive to catechins. Olosunde et al. [76] employed tested alkaloids, carbohydrates, flavonoids, saponins, steroids, tannins, and terpenes in tea. The antimicrobial effects of tea methanolic and aqueous extracts on 4 standard E. coli, P. aeruginosa, S. aureus, and Bacillus subtilis strains were also determined by standard methods. Studied tea extracts evidenced antimicrobial effects 
against E. coli, S. aureus, B. subtilis, and P. aeruginosa, besides also containing tannins and reducing sugars. Black and green tea extracts also exerted growth inhibitory effects on C. jejuni and Campylobacter coli clinical isolates [77]. Tea extracts studied were able to kill C. jejuni and C. coli within $4 \mathrm{~h}$. As a defense response against herbivores attacks, such as the smaller tea tortrix (Adoxophyes honmai Yasuda), C. sinensis leaves exhales numerous volatiles at higher doses ((Z)-3-hexen-1-ol, linalool, $\alpha$-farnesene, benzyl nitrile, indole, nerolidol, and ocimenes) [64].

\section{Environmental Stress Tolerance by Camellia sinensis}

Drought is one of the major environmental factors which globally affect crop production [78]. Global arid and semi-arid regions account for about $36 \%$ of the total land area and $43 \%$ of arable land. C. sinensis primarily grown in rain fed tropical areas. Inconsistent distributions of annual rainfall can result in tea plants' moisture stress. Indeed, water stress affects biochemical constituents that determine tea quality. Soil moisture stress causes phenylalanine ammonia lyase (PAL) activity reduction, and lower PAL activity is correlated with lower synthesis of flavones, such as EGCG and ECG $[79,80]$. Amplified fragment length polymorphism (AFLP) fingerprints were developed for 29 tea clones. Drought-specific superoxide dismutase (SOD) and ascorbate peroxidase (APX) isozyme activity was found to be appreciably high. Regression analysis of $\mathrm{Cu}-\mathrm{Zn}$ /SOD and APX-II, as dependent variables, and random amplified polymorphic DNA (RAPD) band scores, as an independent variable, revealed that OPAH02 primed DNA band at $1400 \mathrm{bp}$ was associated with high drought tolerance-specific isozymes activity. Using Fisher's exact test, this association was found to be at $99.9 \%$ confidence level [81].

C. sinensis plants' response to physiological and biochemical parameters, like moisture stress, was evaluated in order to identify drought tolerance-associated traits using field grown, mature plants in the Field Gene Bank at Passara, Sri Lanka. Main parameters that could be successfully incorporated into a drought screening procedure included relative water content, total soluble sugar content, photosynthesis rate, transpiration rate, and stomatal conductance [82]. Similarly, deepening knowledge on genes that govern $C$. sinensis architecture and drought stress response are also of utmost importance to enhance tea breeding with improved water use efficiency [83]. This research was done before $C$. sinensis wilting and recovery stages, and it was revealed that there are a set of genes with higher pre-wilting expression, including dehydrin, abscisic acid ripening protein, glutathione peroxidase, cinnamoyl CoA reductase, and calmodulin binding protein. It was also observed that physiological parameters, such as water use efficiency, formed a close group with genes.

\section{Conclusions}

C. sinensis contains secondary metabolites, among them phenolic compounds, which are broadly considered as renowned tea quality parameters, in addition to playing a crucial role as antimicrobials and antioxidants. On the other hand, endophytic bacteria also play an interesting role in stimulating secondary metabolite production, besides promoting green tea growth through inducing indole acetic acid production, phosphate solubilization, and ammonia production, exerting antagonism against pathogens and promoting siderophore production. Nevertheless, this biological phenomenon occurring in green tea was only revealed through using transcriptomics, proteomics, and metabolomics analysis. In addition, the role of environmental factors affecting $C$. sinensis leaves' phytochemical composition can also be studied with omics technologies for better understanding and control of the phytochemical composition, which has a marked impact on tea quality parameters and even in biological functions, including antioxidant and antimicrobial properties.

Thus, considering the highlighted aspects, this review may be considered the basis of future prospects that lead to the determination of Athrixia phylicoides DC. (bush tea) metabolic profiles. Indeed, bush tea is a shrub indigenous to South Africa, and naturally grows in Limpopo, Mpumalanga, Eastern Cape, and KwaZulu-Natal provinces of the country, which has gained a high popularity countrywide as a healthy beverage [84,85]. Thus, given the renowned health benefits of its leaves for cleansing 
blood and treating ailments, such as boils, headaches, infested wounds, and coughs, the use of this "omics" discipline may be promising in studying the plant metabolic responses to different treatments. In fact, it is assumed that different $A$. phylicoides treatments with bacteria are able to trigger various metabolic responses.

Author Contributions: All authors (P.P.T., K.N., F.N.M., B.S., M.S.-R., N.M., M.M., and J.S.-R.) contributed equally to this work. B.S., J.S.-R., and N.M. critically reviewed the manuscript. All the authors read and approved the final manuscript.

Acknowledgments: This work was supported by CONICYT PIA/APOYO CCTE AFB170007. N. Martins would like to thank the Portuguese Foundation for Science and Technology (FCT-Portugal) for the Strategic project ref. UID/BIM/04293/2013 and "NORTE2020-Programa Operacional Regional do Norte" (NORTE-01-0145-FEDER-000012).

Conflicts of Interest: The authors declare no conflict of interest.

\section{Abbreviations}

$\begin{array}{ll}\text { 2DPAGE } & \text { two-dimensional polyacrylamide gel electrophoresis } \\ \text { AFLP } & \text { amplified fragment length polymorphism } \\ \text { AGP } & \text { arabinogalactan proteins } \\ \text { APX } & \text { ascorbate peroxidase } \\ \text { BHA } & \text { butylated hydroxyanisole } \\ \text { BL-SOM } & \text { batch-learning self-organizing map } \\ \text { DA } & \text { discriminant analysis } \\ \text { EC } & \text { epicatechin } \\ \text { EGC } & \text { epigallocatechin } \\ \text { EGCG } & \text { epigallocatechin-3-gallate } \\ \text { ELISA } & \text { enzyme-linked immunosorbent assay } \\ \text { EST } & \text { expressed sequence tag } \\ \text { HPLC } & \text { high performance liquid chromatography } \\ \text { IBA } & \text { indole-3-butyric acid } \\ \text { GC } & \text { gas chromatography } \\ \text { GCG } & \text { epigallocatechin-3-gallate } \\ \text { IAA } & \text { indole-3-acetic acid } \\ \text { LC } & \text { liquid chromatography } \\ \text { MALDI-TOF } & \text { matrix-assisted laser desorption-ionization time-of-flight } \\ \text { MIC } & \text { minimum inhibitory concentration } \\ \text { MS } & \text { mass spectrometry } \\ \text { NMR } & \text { Nuclear Magnetic Resonance } \\ \text { OPLS } & \text { orthogonal projections to latent structures } \\ \text { PAL } & \text { phenylalanine ammonia lyase } \\ \text { PCA } & \text { principal component analysis } \\ \text { PGPR } & \text { plant growth promoting rhizobacteria } \\ \text { PSB } & \text { phosphate-solubilizing bacteria } \\ \text { SAR } & \text { systemic acquired resistance } \\ \text { PLS } & \text { partial least squares } \\ \text { RAPD } & \text { random amplified polymorphic DNA } \\ \text { SOD } & \text { superoxide dismutase } \\ & \end{array}$

\section{References}

1. Carloni, P.; Tiano, L.; Padella, L.; Bacchetti, T.; Customu, C.; Kay, A.; Damiani, E. Antioxidant activity of white, green and black tea obtained from the same tea cultivar. Food Res. Int. 2013, 53, 900-908. [CrossRef]

2. Morang, P.; Dutta, B.K.; Kumar, B.S.D.; Kashyap, M.P. Growth promotion and bi-control approaches of brown root rot disease of tea by Pseudomonas aeruginosa (PM 105). J. Plant Pathol. Microbiol. 2012, 3, 1-4. [CrossRef] 
3. Scherling, C.; Ulrich, K.; Ewald, D.; Weckwerth, W. A metabolic signature of the beneficial interaction of the Endophyte paenibacillus sp. Isolate and in vitro-grown poplar plants revealed by metabolomics. Mol. Plant-Microbe Interact. 2009, 22, 1032-1037. [CrossRef]

4. Perva-Uzunalić, A.; Škerget, M.; Knez, Ž.; Weinreich, B.; Otto, F.; Grüner, S. Extraction of active ingredients from green tea (Camellia sinensis): Extraction efficiency of major catechins and caffeine. Food Chem. 2006, 96, 597-605. [CrossRef]

5. Namita, P.; Mukesh, R.; Vijay, K. Camellia sinensis (green tea): A review. Glob. J. Pharmacol. 2012, 6, 52-59.

6. Yang, Y.; Tang, Q.; Liu, H.; Qiu, D. Tree omics and biotechnology in china. Plant OMICS 2011, 4, $288-294$.

7. Commisso, M.; Strazzer, P.; Toffali, K.; Stocchero, M.; Guzzo, F. Untargeted metabolomics: An emerging approach to determine the composition of herbal products. Comput. Struct. Biotechnol. J. 2013, 4, e201301007. [CrossRef] [PubMed]

8. Mahmood, T.; Akhtar, N.; Khan, B.A. The morphology, characteristics, and medicinal properties of Camellia sinensis' tea. J. Med. Plants Res. 2010, 4, 2028-2033.

9. Mbata, T.I. Preliminary studies of the antibacterial activities of processed kenyan and nigerian tea. Afr. J. Biotechnol. 2007, 6, 278-279.

10. Ahmed, M.; Hussain, M.; Dhar, M.K.; Kaul, S. Isolation of microbial endophytes from some ethnomedicinal plants of Jammu and Kashmir. J. Nat. Prod. Plant Resour. 2012, 2, 215-220.

11. Ryan, R.P.; Germaine, K.; Franks, A.; Ryan, D.J.; Dowling, D.N. Bacterial endophytes: Recent developments and applications. FEMS Microbiol. Lett. 2008, 278, 1-9. [CrossRef] [PubMed]

12. Joyce, A.R.; Palsson, B.O. The model organism as a system: Integrating 'omics' data sets. Nat. Rev. Mol. Cell Biol. 2006, 7, 198-210. [CrossRef]

13. Gehlenborg, N.; O’Donoghue, S.I.; Baliga, N.S.; Goesmann, A.; Hibbs, M.A.; Kitano, H.; Kohlbacher, O.; Neuweger, H.; Schneider, R.; Tenenbaum, D.; et al. Visualization of omics data for systems biology. Nat. methods 2010, 7, S56-S68. [CrossRef] [PubMed]

14. Wang, X.-C.; Zhao, Q.-Y.; Ma, C.-L.; Zhang, Z.-H.; Cao, H.-L.; Kong, Y.-M.; Yue, C.; Hao, X.-Y.; Chen, L.; Ma, J.-Q.; et al. Global transcriptome profiles of Camellia sinensis during cold acclimation. BMC Genom. 2013, 14, 415. [CrossRef] [PubMed]

15. Shi, C.-Y.; Yang, H.; Wei, C.-L.; Yu, O.; Zhang, Z.-Z.; Jiang, C.-J.; Sun, J.; Li, Y.-Y.; Chen, Q.; Xia, T.; et al. Deep sequencing of the Camellia sinensis transcriptome revealed candidate genes for major metabolic pathways of tea-specific compounds. BMC Genom. 2011, 12, 131. [CrossRef] [PubMed]

16. Tan, L.Q.; Wang, L.Y.; Wei, K.; Zhang, C.C.; Wu, L.Y.; Qi, G.N.; Cheng, H.; Zhang, Q.; Cui, Q.M.; Liang, J.B. Floral transcriptome sequencing for ssr marker development and linkage map construction in the tea plant (Camellia sinensis). PLoS ONE 2013, 8, e81611. [CrossRef] [PubMed]

17. Zhu, Q.W.; Luo, Y.P. Identification of mirnas and their targets in tea (Camellia sinensis). J. Zhejiang Univ. Sci. B 2013, 14, 916-923. [CrossRef]

18. Jaiprakash, M.R.; Pillai, B.; Venkatesh, P.; Subramanian, N.; Sinkar, V.P.; Sadhale, P.P. Rna isolation from high-phenolic freeze-dried tea (Camellia sinensis) leaves. Plant Mol. Biol. Rep. 2003, 21, 465-466. [CrossRef]

19. Wang, M.; Zhang, X.; Li, Q.; Chen, X.; Li, X. Comparative transcriptome analysis to elucidate the enhanced thermotolerance of tea plants (Camellia sinensis) treated with exogenous calcium. Planta 2018. [CrossRef] [PubMed]

20. Verheggen, K.; Martens, L.; Berven, F.S.; Barsnes, H.; Vaudel, M. Database search engines: Paradigms, challenges and solutions. Adv. Exp. Med. Biol. 2016, 919, 147-156.

21. Chi, H.; Liu, C.; Yang, H.; Zeng, W.-F.; Wu, L.; Zhou, W.-J.; Wang, R.-M.; Niu, X.-N.; Ding, Y.-H.; Zhang, Y.; et al. Comprehensive identification of peptides in tandem mass spectra using an efficient open search engine. Nat. Biotechnol. 2018, 36, 1059-1061. [CrossRef] [PubMed]

22. Ke, M.; Shen, L.; Luo, S.; Lin, L.; Yang, J.; Tian, R. Identification, quantification, and site localization of protein posttranslational modifications via mass spectrometry-based proteomics. In Modern Proteomics—Sample Preparation, Analysis and Practical Applications. Advances in Experimental Medicine and Biology; Mirzaei, M., Carrasco, M., Eds.; Springer: Berlin/Heidelberg, Germany, 2016; Volume 919, pp. 345-381.

23. Li, J.; Chen, J.; Zhang, Z.; Pan, Y. Proteome analysis of tea pollen (Camellia sinensis) under different storage conditions. J. Agric. Food Chem. 2008, 56, 7535-7544. [CrossRef] 
24. Zhou, X.L.; Sun, P.N.; Bucheli, P.; Huang, T.H.; Wang, D. Ft-ir methodology for quality control of arabinogalactan protein (AGP) extracted from green tea (Camellia sinensis). J. Agric. Food Chem. 2009, 57, 5121-5128. [CrossRef]

25. Tugizimana, F.; Steenkamp, P.A.; Piater, L.A.; Dubery, I.A. Ergosterol-induced sesquiterpenoid synthesis in tobacco cells. Molecules 2012, 17, 1698-1715. [CrossRef] [PubMed]

26. Krafova, K.; Jampilek, J.; Ostrovsky, I. Metabolomics in research of phytotherapeutics. Ceska Slov. Farm. Cas. Ceske Farm. Spol. Slov. Farm. Spol. 2012, 61, 21-25.

27. Okada, T.; Afendi, F.M.; Altaf-Ul-Amin, M.; Takahashi, H.; Nakamura, K.; Kanaya, S. Metabolomics of medicinal plants: The importance of multivariate analysis of analytical chemistry data. Curr. Comput.-Aided Drug Des. 2010, 6, 179-196. [CrossRef]

28. Barchet, G. A Brief Overview of Metabolomics: What It Means, How It Is Measured, and Its Utilization. Available online: http:/ /www.scq.ubc.ca/a-brief-overview-of-metabolomics-what-it-means-how-it-ismeasured-and-its-utilization (accessed on 19 August 2017).

29. Roessner, U.; Bowne, J. What is metabolomics all about? BioTechniques 2009, 46, 363-365. [CrossRef]

30. Shyur, L.F.; Yang, N.S. Metabolomics for phytomedicine research and drug development. Curr. Opin. Chem. Biol. 2008, 12, 66-71. [CrossRef]

31. Sharifi-Rad, M.; Nazaruk, J.; Polito, L.; Morais-Braga, M.; Rocha, J.; Coutinho, H.; Salehi, B.; Tabanelli, G.; Montanari, C.; Del, M.M.C. Matricaria genus as a source of antimicrobial agents: From farm to pharmacy and food applications. Microbiol. Res. 2018, 215, 76-88. [CrossRef]

32. Mishra, P.A.; Sharifi-Rad, M.; Shariati, M.; Mabkhot, Y.; Al-Showiman, S.; Rauf, A.; Salehi, B.; Župunski, M.; Sharifi-Rad, M.; Gusain, P. Bioactive compounds and health benefits of edible Rumex species-a review. Cell. Mol. Biol. (Noisy-le-Grand, France) 2018, 64, 27-34. [CrossRef]

33. Sharifi-Rad, M.; Roberts, T.; Matthews, K.; Bezerra, C.; Morais-Braga, M.; Coutinho, H.; Sharopov, F.; Salehi, B.; Yousaf, Z.; Del, M.M.C. Ethnobotany of the genus Taraxacum-phytochemicals and antimicrobial activity. Phytother. Res. 2018, 32, 2131-2145. [CrossRef]

34. Mishra, A.P.; Saklani, S.; Salehi, B.; Parcha, V.; Sharifi-Rad, M.; Milella, L.; Iriti, M.; Sharifi-Rad, J.; Srivastava, M. Satyrium nepalense, a high altitude medicinal orchid of indian himalayan region: Chemical profile and biological activities of tuber extracts. Cell. Mol. Biol. (Noisy-le-Grand, France) 2018, 64, 35-43. [CrossRef]

35. Azevedo, R.S.A.; Teixeira, B.S.; Sauthier, M.; Santana, M.V.A.; Dos Santos, W.N.L.; Santana, D.A. Multivariate analysis of the composition of bioactive in tea of the species Camellia sinensis. Food Chem. 2019, 273, 39-44. [CrossRef] [PubMed]

36. Harbowy, M.E.; Balentine, D.A.; Davies, A.P.; Cai, Y. Tea chemistry. Crit. Rev. Plant Sci. 1997, 16, 415-480. [CrossRef]

37. Punyasiri, P.A.; Abeysinghe, I.S.; Kumar, V.; Treutter, D.; Duy, D.; Gosch, C.; Martens, S.; Forkmann, G.; Fischer, T.C. Flavonoid biosynthesis in the tea plant Camellia sinensis: properties of enzymes of the prominent epicatechin and catechin pathways. Arch Biochem Biophys. 2004, 431, 22-30. [CrossRef] [PubMed]

38. Le Gall, G.; Colquhoun, I.J.; Defernez, M. Metabolite profiling using $1 \mathrm{~h} \mathrm{nmr}$ spectroscopy for quality assessment of green tea, Camellia sinensis (L.). J. Agric. Food Chem. 2004, 52, 692-700. [CrossRef] [PubMed]

39. Liu, L.; Li, Y.; She, G.; Zhang, X.; Jordan, B.; Chen, Q.; Zhao, J.; Wan, X. Metabolite profiling and transcriptomic analyses reveal an essential role of uvr8-mediated signal transduction pathway in regulating flavonoid biosynthesis in tea plants (Camellia sinensis) in response to shading. BMC Plant Biol. 2018, 18, 233. [CrossRef]

40. Ku, K.M.; Choi, J.N.; Kim, J.; Kim, J.K.; Yoo, L.G.; Lee, S.J.; Hong, Y.S.; Lee, C.H. Metabolomics analysis reveals the compositional differences of shade grown tea (Camellia sinensis L.). J. Agric. Food Chem. 2010, 58, 418-426. [CrossRef]

41. Lee, J.-E.; Lee, B.-J.; Chung, J.-O.; Hwang, J.-A.; Lee, S.-J.; Lee, C.-H.; Hong, Y.-S. Geographical and climatic dependencies of green tea (Camellia sinensis) metabolites: A 1h NMR-based metabolomics study. J. Agric. Food Chem. 2010, 58, 10582-10589. [CrossRef]

42. Lee, J.E.; Lee, B.J.; Hwang, J.A.; Ko, K.S.; Chung, J.O.; Kim, E.H.; Lee, S.J.; Hong, Y.S. Metabolic dependence of green tea on plucking positions revisited: A metabolomic study. J. Agric. Food Chem. 2011, 59, 10579-10585. [CrossRef] 
43. Yao, L.; Caffin, N.; D’Arcy, B.; Jiang, Y.; Shi, J.; Singanusong, R.; Liu, X.; Datta, N.; Kakuda, Y.; Xu, Y. Seasonal variations of phenolic compounds in australia-grown tea (Camellia sinensis). J. Agric. Food Chem. 2005, 53, 6477-6483. [CrossRef] [PubMed]

44. Pongsuwan, W.; Fukusaki, E.; Bamba, T.; Yonetani, T.; Yamahara, T.; Kobayashi, A. Prediction of japanese green tea ranking by gas chromatography/mass spectrometry-based hydrophilic metabolite fingerprinting. J. Agric. Food Chem. 2007, 55, 231-236. [CrossRef] [PubMed]

45. Singh, H.P.; Ravindranath, S.D.; Singh, C. Analysis of tea shoot catechins: Spectrophotometric quantitation and selective visualization on two-dimensional paper chromatograms using diazotized sulfanilamide. J. Agric. Food Chem. 1999, 47, 1041-1045. [CrossRef] [PubMed]

46. Bokuchava, M.A.; Skobeleva, N.I. The chemistry and biochemistry of tea and tea manufacture. In Advances in Food Research; Chichester, C.O., Mrak, E.M., Stewart, G.F., Eds.; Academic Press: Waltham, MA, USA, 1969; Volume 17, pp. 215-292.

47. Chakraborty, U.; Chakraborty, B.; Basnet, M. Plant growth promotion and induction of resistance in Camellia sinensis by Bacillus megaterium. J. Basic Microbiol. 2006, 46, 186-195. [CrossRef]

48. Chakraborty, U.; Chakraborty, B.N.; Chakraborty, A.P. Evaluation of Bacillus megaterium and Serratia marcescens and their bioformulations for promoting growth of Camellia sinensis. Int. J. Tea Sci. (IJTS) 2011, 8, 69-80.

49. Chakraborty, U.; Chakraborty, B.N.; Chakraborty, A.P. Induction of plant growth promotion in Camellia sinensis by Bacillus megaterium and its bioformulations. World J. Agric. Sci. 2012, 8, 104-112.

50. Nepolean, P.; Jayanthi, R.; Pallavi, R.V.; Balamurugan, A.; Kuberan, T.; Beulah, T.; Premkumar, R. Role of biofertilizers in increasing tea productivity. Asian Pacif. J. Trop. Biomed. 2012, 2, S1443-S1445. [CrossRef]

51. Tennakoon, P.L.K. Studies on Plant Growth Promoting Rhizomicroorganisms of Tea (Camellia sinensis (L.) Kuntze) Plants. Master's Thesis, University of Agriculture Sciences, Dharwad, Karnataka, India, 2007.

52. Erturk, Y.; Ercisli, S.; Sekban, R.; Haznedar, A.; Donmez, M.F. The effect of pgpr on rooting and growth of tea (Camellia sinensis Var. Sinensis) cuttings. Roman. Biotechnol. Lett. 2008, 13, 3747-3756.

53. Nath, R.; Sharma, G.D.; Barooah, M. Screening of endophytic bacterial isolates of tea (Camellia sinensis L.) roots for their multiple plant growth promoting activities. Int. J. Agric. Environ. Biotechnol. 2013, 6, 211-215.

54. Guo, B.; Wang, Y.; Sun, X.; Tang, K. Bioactive natural products from endophytes: A review. Prikl. Biokhimiia Mikrobiol. 2008, 44, 153-158. [CrossRef]

55. Tan, R.X.; Zou, W.X. Endophytes: A rich source of functional metabolites. Nat. Prod. Rep. 2001, 18, 448-459. [CrossRef] [PubMed]

56. Rosenblueth, M.; Martinez-Romero, E. Bacterial endophytes and their interactions with hosts. Mol. Plant-Microbe Interact. MPMI 2006, 19, 827-837. [CrossRef] [PubMed]

57. Shan, W.; Zhou, Y.; Liu, H.; Yu, X. Endophytic actinomycetes from tea plants (Camellia sinensis): Isolation, abundance, antimicrobial, and plant-growth-promoting activities. BioMed Res. Int. 2018, 2018, 1470305. [CrossRef] [PubMed]

58. Chakraborty, U.; Chakraborty, B.N.; Chakraborty, A.P. Plant growth promoting activity of Bacillus pumilus in tea (Camellia sinensis) and its biocontrol potential against poria hypobrunnea. Indian Phytopath 2013, 66, 387-396.

59. Chakraborty, U.; Chakraborty, B.N.; Chakraborty, A.P.; Sunar, K.; Dey, P.L. Plant growth promoting rhizobacteria mediated improvement of health status of tea plants. Indian J. Biotechnol. 2013, 12, $20-31$.

60. Phukan, I.; Madhab, M.; Bordoloi, M.; Sarmah, S.R.; Dutta, P.; Begum, R.; Tanti, A.; Bora, S.; Nair, S.C.; Rai, S.; et al. Exploitation of PGP microbes of tea for improvement of plant growth and pest suppression: Anovel approach. Two Bud 2012, 59, 69-74.

61. Tanaka, T.; Mine, C.; Watarumi, S.; Fujioka, T.; Mihashi, K.; Zhang, Y.J.; Kouno, I. Accumulation of epigallocatechin quinone dimers during tea fermentation and formation of theasinensins. J. Nat. Prod. 2002, 65, 1582-1587. [CrossRef] [PubMed]

62. Mbata, T.I.; Debiao, L.U.; Saikia, A. Antibacterial activity of the crude extract of chinese green tea (Camellia sinensis) on listeria monocytogenes. Afr. J. Biotechnol. 2008, 7, 1571-1573.

63. Hara-Kudo, Y.; Yamasaki, A.; Sasaki, M.; Okubo, T.; Minai, Y.; Haga, M.; Kondo, K.; Sugita-Konishi, Y. Antibacterial action on pathogenic bacterial spore by green tea catechins. J. Sci. Food Agric. 2005, 85, 2354-2361. [CrossRef] 
64. Dong, F.; Yang, Z.; Baldermann, S.; Sato, Y.; Asai, T.; Watanabe, N. Herbivore-induced volatiles from tea (Camellia sinensis) plants and their involvement in intraplant communication and changes in endogenous nonvolatile metabolites. J. Agric. Food Chem. 2011, 59, 13131-13135. [CrossRef]

65. Zambare, V.; Bhoyte, S. Antimicrobial activity of tea (Camellia sinensis). Biomed. Pharmacol. J. 2009, 2, $173-175$.

66. Kumar, A.; Kumar, A.; Thakur, P.; Patil, S.; Payal, C.; Kumar, A.; Sharma, P. Antibacterial activity of green tea (Camellia sinensis) extracts against various bacteria isolated from environmental sources. Recent Res. Sci. Technol. 2012, 4, 19-23.

67. Mandal, S.; DebMandal, M.; Pal, N.K.; Saha, K. Inhibitory and killing activities of black tea (Camellia sinensis) extract against salmonella enterica serovar typhi and Vibrio cholerae O1 biotype el tor serotype ogawa isolates. Jundishapur J. Microbiol. 2011, 4, 115-121.

68. Rozoy, E.; Bazinet, L.; Araya-Farias, M.; Guernec, A.; Saucier, L. Inhibitory effects of commercial and enriched green tea extracts on the growth of Brochothrix thermosphacta, Pseudomonas putida and Escherichia coli. J. Food Res. 2013, 2, 1-7. [CrossRef]

69. Archana, S.; Abraham, J. Comparative analysis of antimicrobial activity of leaf extracts from fresh green tea, commercial green tea and black tea on pathogens. J. Appl. Pharm. Sci. 2011, 1, 149-152.

70. Chan, E.W.; Soh, E.Y.; Tie, P.P.; Law, Y.P. Antioxidant and antibacterial properties of green, black, and herbal teas of Camellia sinensis. Pharmacogn. Res. 2011, 3, 266-272. [CrossRef]

71. Reygaert, W.C. Green tea catechins: Their use in treating and preventing infectious diseases. BioMed Res. Int. 2018, 2018, 9105261. [CrossRef]

72. Lee, J.H.; Shim, J.S.; Lee, J.S.; Kim, J.K.; Yang, I.S.; Chung, M.S.; Kim, K.H. Inhibition of pathogenic bacterial adhesion by acidic polysaccharide from green tea (Camellia sinensis). J. Agric. Food Chem. 2006, 54, 8717-8723. [CrossRef]

73. Axelrod, M.L.; Berkowitz, S.T.; Dhir, R.; Gould, V.F.; Gupta, A.; Li, E.I.; Park, J.; Shah, A.N.; Shi, K.; Tan, C.X.; et al. The Inhibitory Effects of Green Tea (Camellia Sinensis) on the Growth and Proliferation of Oral Bacteria. J. New Jersey Gov. Sch. 2010, 3, 1-19.

74. Akroum, S. Antifungal activity of camellia sinensis crude extracts against four species of candida and microsporum persicolor. J. Mycol. Med. 2018, 28, 424-427. [CrossRef]

75. Simonetti, G.; Simonetti, N.; Villa, A. Increased microbicidal activity of green tea (Camellia sinensis) in combination with butylated hydroxyanisole. J. Chemother. (Florence, Italy) 2004, 16, 122-127. [CrossRef] [PubMed]

76. Olosunde, O.F.; Abu-Saeed, K.; Abu-Saeed, M.B. Phytochemical screening and antimicrobial properties of a common brand of black tea (Camellia sinensis) marketed in nigerian environment. Adv. Pharm. Bull. 2012, 2, 259-263. [PubMed]

77. Diker, K.S.; Akan, M.; Hascelik, G.; Yurdakök, M. The bactericidal activity of tea against Campylobacter jejuni and Campylobacter coli. Lett. Appl. Microbiol. 1991, 12, 34-35. [CrossRef]

78. Qi, G.; Xia, J.; Chen, S.; Chen, Y. Mrna differential display of tea leaves under polyethylene glycol stress. J. Agric. Sci. 2010, 2, 186-190.

79. Cheruiyot, E.K.; Mumera, L.M.; Ng'Etich, W.K.; Hassanali, A.; Wachira, F. Polyphenols as potential indicators for drought tolerance in tea (Camellia sinensis L.). Biosci. Biotechnol. Biochem. 2007, 71, 2190-2197. [CrossRef] [PubMed]

80. Waheed, A.; Hamid, F.S.; Shah, A.H.; Ahmad, H.; Khalid, A.; Abbasi, F.M.; Ahmad, N.; Aslam, S.; Sarwar, S. Response of different tea (Camellia sinensis L.) clones against drought stress. J. Mater. Environ. Sci. 2012, 3, 395-410.

81. Mishra, R.K.; Sen-Mandi, S. Molecular profiling and development of DNA marker associated with drought tolerance in tea clones growing in Darjeeling. Curr. Sci. India 2004, 87, 60-66.

82. Damayanthi, M.N.M.; Mohotti, A.J.; Nissanka, S.P. Comparison of tolerant ability of mature field grown tea (Camellia sinensis 1.) cultivars exposed to a drought stress in passara area. Trop. Agric. Res. 2011, 22, 66-75. [CrossRef]

83. Gupta, S.; Bharalee, R.; Bhorali, P.; Bandyopadhyay, T.; Gohain, B.; Agarwal, N.; Ahmed, P.; Saikia, H.; Borchetia, S.; Kalita, M.C.; et al. Identification of drought tolerant progenies in tea by gene expression analysis. Funct. Integr. Genom. 2012, 12, 543-563. [CrossRef] 
84. Joubert, E.; Gelderblom, W.C.; Louw, A.; de Beer, D. South african herbal teas: Aspalathus linearis, Cyclopia spp. And athrixia phylicoides-a review. J. Ethnopharmacol. 2008, 119, 376-412. [CrossRef]

85. Lerotholi, L.J.; Chaudhary, S.K.; Chen, W.; Veale, C.G.L.; Combrinck, S.; Viljoen, A.M. Identification, isolation and determination of biomarkers for quality control of bush tea (Athrixia phyllicoides). Planta Med. 2018, 84, 902-912. [CrossRef] [PubMed] 